\title{
Plant evolutionary ecology in mountain regions in space and time
}

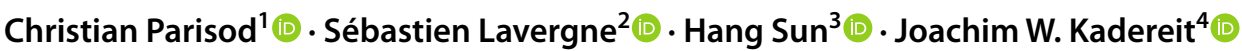

Received: 12 January 2022 / Accepted: 25 January 2022 / Published online: 12 February 2022

(c) The Author(s) 2022

\begin{abstract}
This special issue of the journal Alpine Botany brings together syntheses, macroecological and taxon-specific studies of patterns and processes of plant evolution in major mountain ranges across Europe, Africa, the Americas and Asia. Apart from reflecting current conceptual and methodological perspectives in the field, it contributes to our understanding of the interplay between factors determining the evolution and distribution of plant variation across topographically complex areas, and will help to identify the components necessary for building an integrative model of the origin and distribution of diversity in mountain areas.
\end{abstract}

Keywords Alpine biogeography $\cdot$ Biodiversity $\cdot$ Environmental heterogeneity $\cdot$ Plant diversification

Latitudinal and elevational gradients are increasingly investigated to understand ecological and evolutionary processes underlying patterns of biodiversity (e.g. Rangel et al. 2018). Although mountain regions contribute disproportionally to plant diversity (Körner 2021), the reasons for this are not yet fully understood and current hypotheses still fail to completely "explain this Humboldt's enigma" (Rahbek et al. 2019). Indeed, despite Stebbins' early reasoning about the role of specific mountain regions as museums, cradles or even graves of biodiversity (Stebbins 1974),

Christian Parisod

christian.parisod@unifr.ch

Sébastien Lavergne

sebastien.lavergne@univ-grenoble-alpes.fr

Hang Sun

sunhang@mail.kib.ac.cn

Joachim W. Kadereit

kadereit@uni-mainz.de

1 Department of Biology, University of Fribourg, Chemin du Musée 10, CH-1700 Fribourg, Switzerland

2 Laboratoire d'Ecologie Alpine, University of Grenoble Alpes, University of Savoie Mont Blanc, CNRS, Gières, France

3 CAS Key Laboratory for Plant Diversity and Biogeography, Kunming Institute of Botany, Chinese Academy of Sciences, No 132, Lanhei Road, Kunming 650201, Yunnan, China

4 Institut für Organismische und Molekulare Evolutionsbiologie, Johannes Gutenberg-Universität Mainz, 55099 Mainz, Germany firm conclusions on this matter have not yet been reached (Antonelli et al. 2018; McFadden et al. 2019).

Topographically complex mountain regions differ from their lowland surroundings by encompassing remarkable ecological heterogeneity over short spatial distances. In particular, shortening of the yearly growing periods with increasing elevation strongly constraints the distribution and the adaptation of species and communities, and this translates into highly complex responses to climatic variation through time. Investigating evolutionary lineages from mountain regions accordingly enables to assess outcomes of stochastic and adaptive processes, and can help to disentangle signals left by biogeographical processes in space and time. The field of alpine botany can greatly contribute to our fundamental understanding of drivers of the distribution and evolution of taxa.

Case studies of alpine botany are traditionally published in a variety of journals with varied scopes, making it difficult to achieve a unified overview of patterns and processes acting in different mountain ranges. This special issue of the journal Alpine Botany brings together syntheses, macroecological and taxon-specific studies of patterns and processes of plant evolution in major mountain ranges across Europe, Africa, the Americas and Asia. Apart from reflecting current conceptual and methodological perspectives in the field, we hope that this special issue will contribute to deepening our understanding of the interplay between factors determining the evolution and distribution of plant variation across topographically complex areas, and will help to identify the 
components necessary for building an integrative model of the origin and distribution of diversity in mountain areas.

This issue starts with a methodological review paper by Larsson et al. (2021) on alpine Quaternary phylogeography. They not only provide a brief historical account of approaches in alpine phylogeography, but also describe the recent integration of distributional, demographic and coalescent (iDDC) modeling as a promising tool. According to them, this approach can be used to reliably infer the historical range shifts of alpine species and to efficiently test long-standing hypotheses such as the location of Quaternary glacial refugia. Despite challenges inherent to the accurate characterization of ecological factors across mountains, this paper shows one way to integrate distribution, demography and genetic relationships through time and how the comparison of hypothesis-driven scenarios yields increasingly credible inferences.

The European Alpine System, with its long-investigated and well-known flora, has been the starting point for many aspects of alpine biogeography. Parisod (2021) synthesizes our current knowledge of the main drivers of speciation in the continuous mountain range of the Alps. As the Alps have been very strongly affected by the climatic oscillations of the Quaternary, cycles of range contraction expansion appear to have resulted in homogenizing gene flow that counteracted speciation in many cases but also fostered the origin of hybrid species.

The analysis of the European clades of Gentiana by Favre et al. (2021) reveals an evolutionary radiation that has been driven by hybridization, polyploidy and chromosomal rearrangements. Noticeably, edaphic differentiation is a major factor structuring the diversity of European Gentiana. This makes it a promising study system to further examine the role of edaphic speciation in the evolution of plant lineages in the Alps.

Studying a subgroup of Campanula from the Pyrenees, Roquet et al. (2021) demonstrate the recent allopatric origin of two species distributed in the Central and Eastern Pyrenees plus Catalan Pre-Pyrenees, respectively, thus providing support for a recently advocated model of transverse speciation in mountain ranges. This is a timely reminder that spatio-temporal processes underlying biodiversity are far from being completely understood, that important discoveries for conservation management can be made even in well-explored mountain ranges.

East African high mountains have long fascinated botanists as "sky islands" for alpine plants. Revisiting classical hypotheses concerning the Afroalpine flora in the light of recent findings from densely sampled molecular and niche modelling studies, Brochmann et al. (2021) highlight the rather recent and only modest diversification of cold-adapted lineages that immigrated, often repeatedly, after the onset of harsh alpine conditions in that region.
Furthermore, the East African sky islands have largely remained isolated from each other and from other temperate regions throughout the climatic oscillations of the Quaternary. Despite rare inter-mountain dispersal, alpine species of the African flora appear genetically depauperate and vulnerable to extinction.

Evolution in the East African high mountains was investigated in great detail by Gizaw et al. (2021) for the iconic giant senecios (Dendrosenecio). Using Hyb-Seq sequence data from 1197 nuclear and 449 plastid loci from 42 samples representing all 11 currently recognized species, they found that lineage diversification started in the Late Miocene when high elevation habitats became first available. In this respect, Dendrosenecio clearly deviates from the mostly young diversification found in other lineages. Although diversification has been largely allopatric, hybridization appears to have played a role in the evolution of the group.

American mountain ranges have been the focus of multiple studies since Humboldt. Here, Figueroa et al. (2021) present a global analysis of the distribution of 2937 native plants across the Andes, Sierras of Central America and mountain ranges of North America. They show that the diversity of alpine plants is highest in the Central Andes and western North America, and that assemblages with lower phylogenetic diversity contained species with a greater degree of alpine specialization. From a comparison of ecologically similar near-Arctic and Patagonian mountain ranges they conclude that abiotic filtering alone is unlikely to explain the structure of alpine species assemblages in the Americas. Their analysis also highlights that assemblages of alpine species mostly consist of phylogenetically related taxa, and that alpine specialists have mostly diversified from pre-adapted lower elevation taxa.

In their molecular phylogenetic study of Oritrophium, as it turned out a non-monophyletic group which diversified largely within and among species-rich Páramo communities of the Andes, Salomón et al. (2021) found that the group likely diversified with the emergence of the Paramo during the Late Pliocene and further dispersed mainly from Southto-North in the Pleistocene. This migration involved both long-distance dispersal from the Central Andes to Mexico and gradual migration of species along the Andes.

East Asian mountain ranges encompass the highest peaks on earth in the Himalayas, the high-elevation Tibetan plateau and the Hengduan Mountains. This enormous diversity of plant species has been subject to large numbers of phylogenetic and biogeographical studies in the recent past, highlighting the north-south-oriented Hengduan Mountain as a channel for plant migration and exchange. In their study of the region, Sun et al. (2021) review the influence of the geological changes in the course of major rivers on plant diversification. They conclude that the reorganization of drainage systems resulted, at different times, in distributional 
Table 1 Key components of a model of alpine plant evolution, highlighting spatial and temporal data that need to be integrated for biogeographical interpretations and for guidelines to conservation

\begin{tabular}{ll}
\hline Mountain ranges & Plant lineages \\
\hline Geological history & Adequate sampling of both inter- and intraspecific diversity \\
Edaphic heterogeneity & $\begin{array}{l}\text { Ecological characterization of taxa (biotic and abiotic) } \\
\text { Climatic history (ideally beyond the last glacial maximum) } \\
\text { History of relationships based on high-resolution molecular markers } \\
\text { (ideally plastid vs nuclear loci) }\end{array}$ \\
Connectivity to other mountain ranges & $\begin{array}{c}\text { Knowledge of other properties (e.g., life-history traits, dispersal, chro- } \\
\text { mosome numbers) }\end{array}$ \\
Environmental data at relevant resolution in space and time & Patterns and processes of variation and diversification in space and time \\
\hline
\end{tabular}

discontinuity preventing East-West migration and leading to both the origin of new taxa and increased North-South genetic exchange.

In their phylogeographic study of (mainly) two species of Acanthocalyx across the Himalaya-Hengduan mountains, $\mathrm{Mu}$ et al. (2021) illustrate how geomorphological features of the region influenced the diversification of its alpine flora and resulted in the origin of important floristic boundaries.

Although all the above contributions add much to our understanding of alpine plant diversity, they collectively also reflect general and specific gaps in our understanding of the origin and distribution of plant diversity in mountain regions. As generally is the case, we remain rather ignorant of the relative impact of stochastic vs. adaptive drivers of the distribution of plant variation within and among species (Vellend 2016). Beyond necessary discussions about the definition of mountains (Körner et al. 2021 and references therein), we still do not know much about the role of specific regions within and among mountain ranges as regards the origin, expansion and demise of plant species. The roles of either orogeny or climate-induced range shifts for speciation and extinction have yet to be comprehensively investigated. For instance, we still hardly understand how to plant diversification is affected by the orientation of mountain chains (e.g. Wallis et al. 2016, Roquet et al. 2021 in this issue). These gaps in knowledge, among others, illustrate that not only additional detailed case studies but also global analyses will be necessary to integrate multidisciplinary knowledge and advance the field. As outlined in Table 1, key components of a model of alpine plant evolution will have to build on the accurate reconstruction of the physical history of mountain ranges and biologically relevant information on taxa under scrutiny. This calls for further coordination of networks and databases across plant phylogeny and phylogeography, geosciences and ecology to promote a satisfactory synthesis in the years to come. Seeking to integrate such multidisciplinary data in space and time, the field of alpine biogeography would greatly benefit from the development of robust methodologies for phylogenetic and phylogeographic analyses as well as appropriate methods to test specific hypotheses. The currently vivid community of alpine botanists is tackling such stimulating challenges towards a better understanding of biodiversity in mountainous areas, which eventually must result in measures for its effective conservation.

Funding Open access funding provided by University of Fribourg.

\section{Declarations}

Conflict of interest The authors have no competing interests to declare that are relevant to the content of this article.

Open Access This article is licensed under a Creative Commons Attribution 4.0 International License, which permits use, sharing, adaptation, distribution and reproduction in any medium or format, as long as you give appropriate credit to the original author(s) and the source, provide a link to the Creative Commons licence, and indicate if changes were made. The images or other third party material in this article are included in the article's Creative Commons licence, unless indicated otherwise in a credit line to the material. If material is not included in the article's Creative Commons licence and your intended use is not permitted by statutory regulation or exceeds the permitted use, you will need to obtain permission directly from the copyright holder. To view a copy of this licence, visit http://creativecommons.org/licenses/by/4.0/.

\section{References}

Antonelli A, Kissling WD, Flantua SGA, Bermúdez MA, Mulch A, Muellner-Riehl AN, Kreft H, Linder HP, Badgley C, Fjeldså J, Fritz SA, Rahbek C, Herman F, Hooghiemstra H, Hoorn C (2018) Geological and climatic influences on mountain biodiversity. Nature Geosci 11:718-725. https://doi.org/10.1038/ s41561-018-0236-Z

Brochmann C, Gizaw A, Chala D, Kandziora M, Eilu G, Popp M, Pirie MD, Gehrke B (2021) History and evolution of the afroalpine flora: in the footsteps of Olov Hedberg. Alp Botany. https://doi. org/10.1007/s00035-021-00256-9

Favre A, Paule J, Ebersbach J (2021) Incongruences between nuclear and plastid phylogenies challenge the identification of correlates of diversification in Gentiana in the European Alpine System. Alp Botany. https://doi.org/10.1007/s00035-021-00267-6

Figueroa HF, Marx HE, de Souza Cortez MB, Grady CJ, Engle-Wrye NJ, Beach J, Stewart A, Folk RA, Soltis DE, Soltis PS, Smith SA (2021) Contrasting patterns of phylogenetic diversity and 
alpine specialization across the alpine flora of the American mountain range system. Alp Botany. https://doi.org/10.1007/ s00035-021-00261-y

Gizaw A, Gorospe JM, Kandziora M, Chala D, Gustafsson L, Zinaw A, Salomón L, Eilu G, Brochmann C, Kolář F, Schmickl R (2021) Afro-alpine flagships revisited II: elucidating the evolutionary relationships and species boundaries in the giant senecios (Dendrosenecio, Asteraceae). Alp Botany. https://doi.org/10.1007/ s00035-021-00268-5

Körner C (2021) Alpine plant life. Springer Nature, Switzerland. https://doi.org/10.1007/978-3-030-59538-8

Körner C, Urbach D, Paulsen J (2021) Mountain definitions and their consequences. Alp Botany 131:213-217. https://doi.org/10.1007/ s00035-021-00265-8

Larsson DJ, Pan Da, Schneeweiss GM (2021) Addressing alpine plant phylogeography using integrative distributional, demographic and coalescent modeling. Alp Botany. https://doi.org/10.1007/ s00035-021-00263-w

McFadden IR, Sandel B, Tsirogiannis C, Morueta-Holme N, Svenning J-C, Enquist BJ, Kraft NJB (2019) Temperature shapes opposing latitudinal gradients of plant taxonomic and phylogenetic $\beta$ diversity. Ecol Lett 22:1126-1135. https://doi.org/10.1111/ele.13269

Mu Q-Y, Yu C-C, Wang Y, Han T-S, Wang H, Ding W-N, Zhang Q-Y, Low SL, Zheng Q-J, Peng C, Hu Z-Y, Xing Y-W (2021) Comparative phylogeography of Acanthocalyx (Caprifoliaceae) reveals distinct genetic structures in the Himalaya-Hengduan Mountains. Alp Botany. https://doi.org/10.1007/s00035-021-00262-x

Parisod C (2021) Plant speciation in the face of recurrent climate changes in the Alps. Alp Botany. https://doi.org/10.1007/ s00035-021-00259-6

Rahbek C, Borregaard MK, Colwell RK, Dalsgaard B, Holt BG, Morueta-Holme N, Nogues-Bravo D, Whittaker RJ, Fjeldså J (2019) Humboldt's enigma: what causes global patterns of mountain biodiversity? Science 365:1108-1113. https://doi.org/10.1126/ science.aax0149

Rangel TF, Edwards NR, Holden PB, Diniz-Filho JAF, Gosling WD, Coelho MTP, Cassemiro FAS, Rahbek C, Colwell RK (2018) Modeling the ecology and evolution of biodiversity: biogeographical cradles, museums, and graves. Science. https://doi.org/ 10.1126/science.aar5452

Roquet C, Smyčka J, Alberti A, Boleda M, Coissac E, Denoeud F, Komac B, Lavergne S, Pladevall C, Sáez L (2021) Evolutionary origins and species delineation of the two Pyrenean endemics Campanula jaubertiana and C. andorrana (Campanulaceae): evidence for transverse alpine speciation. Alp Botany. https://doi.org/ 10.1007/s00035-021-00257-8

Salomón L, Nicola MV, Kandziora M, Kolář F, Sklenář P (2021) Center of origin and evolutionary history in the high Andean genus Oritrophium (Astereae, Asteraceae). Alp Botany. https:// doi.org/10.1007/s00035-021-00271-w

Stebbins GL (1974) Flowering plants, evolution above the species level. Harvard University Press, Cambridge

Sun H, Li Z, Landis JB, Qian L, Zhang T, Deng T (2021) Effects of drainage reorganization on phytogeographic pattern in Sino-Himalaya. Alp Botany. https://doi.org/10.1007/s00035-021-00269-4

Vellend M (2016) The theory of ecological communities. Princeton University Press, Princeton

Wallis GP, Waters JM, Upton P, Craw D (2016) Transverse alpine speciation driven by glaciation. Trends Ecol Evol 31:916-926. https://doi.org/10.1016/j.tree.2016.08.009

Publisher's Note Springer Nature remains neutral with regard to jurisdictional claims in published maps and institutional affiliations. 